\title{
Physical activity Program for Bariatric Surgery Patients at Assuit University Hospital: Post-operative Intervention
}

\author{
Hiam Hammed Mohammed ${ }^{1}$, Safaa Ahmad Mohammed Kotb ${ }^{2}$ \& Safaa Rabea Osman ${ }^{3}$ \\ ${ }^{1 .}$ Nursing Specialist in operating room at Assiut University Hospital, Master degree in Community Health Nursing \\ 2. Professor of Community Health Nursing, Faculty of Nursing, Assiut University, Egypt. \\ ${ }^{3 .}$ Assistant Professor of Community Health Nursing, Faculty of Nursing, Assiut University, Egypt.
}

\begin{abstract}
Obesity is a metabolic disorder, which has become an epidemic worldwide. Bariatric surgery and extended lifestyle adaptation are currently the most effective and long-lasting methods of weight loss. Physical activity (PA) is an essential element of the medical management of patients which subsequent bariatric surgery. Aim of the study: evaluate the effectiveness of physical activity program for bariatric surgery patients. Subjects and method: Quasiexperimental (pre-posttest) research design was used. The study included 70 patients from outpatient's surgery clinic Assiut University Hospital. An interview structured questionnaire was used which included personal characteristics, medical history, and an International physical activity questionnaire. The study was carried through 3 stages: preparatory, implementation, and evaluation stage. Results: There was a highly statistically significant difference (Pvalue $=0.000$ ) between the mean score of pre and post-test physical activity program. It showed that $1.4 \%$ of studied patients had high physical activity in the pretest while in posttest $35.7 \%$ had high physical activity. Conclusion: Physical activity instructions in the postoperative management of patients appear to increase physical activity and maintain weight loss after bariatric surgery. Recommendations: Further studies are needed to confirm these hypotheses with a larger sample size.
\end{abstract}

\section{Keywords: Bariatric surgery, Obesity, Physical activity \& Post-operative intervention.}

\section{Introduction:}

In the Arab region, the prevalence of overweight and obesity has altered significantly during the past three decades. Data from sixteen countries in the region show the highest levels of overweight and obesity in Egypt, Bahrain, Jordan, Kuwait, Saudi Arabia, and the United Arab Emirates. The prevalence in these countries varieties from $74 \%$ to $86 \%$ in women and $69 \%$ to $77 \%$ in men. These data show a much higher prevalence of obesity among adult women, while overweight is more noticeable among adult men (WHO, 2021; Ajlouni et al., 2021).

The World Health Organization (WHO) has cautioned of the accelerating widespread of obesity that could put the population in many countries at the hazard of emerging non-communicable diseases. Overweight and obesity are forceful risk factors for cardiovascular diseases and type II diabetes that leads to premature deaths (WHO, 2021; Bellicha et al., 2021;\& Ajlouni et al., 2021).

Bariatric surgery with different types such as laparoscopic Roux-en-Y gastric bypass has been indicated to greater weight loss than lifestyle interventions for patients who are morbidly obese (Olsén et al., 2021).

The average weight loss after one year from the surgery is nearly $70 \%$ for gastric bypass and $65 \%$ for sleeve gastrostomy, while approximately one-third of patients show failure with $<50 \%$ average weight loss or weight regain in long-term evaluations (Köhler et al., 2020). Lifestyle modifications after bariatric surgery are containing consistent physical activity which is recommended because most patients don't reach recommended points of physical activity after the surgery (Bellicha et al., 2021).

Physical activity (PA) and exercise are necessary to keep the weight healthy and facilitate weight loss and weight stability. Furthermore, PA and exercise can inhibit or support manage the multisystem consequences of obesity as well as preserve overall health and wellbeing (Bellicha et al., 2021).

Community Health Nurse plays an important role in obesity management. Also, she is acting a critical role in maintain weight stability after surgery by promoting healthy behaviors like healthy eating and physical activity. Moreover, nurses should advocate, educate and give best practice guidelines for patients after bariatric surgery (Kawafha, 2013; Upton, 2017; $\&$ Pearce et al., 2019).

Significance of the study:

Weight regain after bariatric surgery comes to be obvious between 12 and 24 months post-operative. Some patients do not reach their planned weight goals, and others recapture a significant percentage of their weight at long-term follow-up. Physical activity is one of the lifestyle modifications recommended after surgery. 
The World Health Organization reported that low levels of physical activity are the $4^{\text {th }}$ important risk factor for worldwide death (about six percent of deaths worldwide) (Vuori, 2018; Ansari \& Elhag, 2021).

Research hypothesis (H1):

There is a relation between the physical activity among bariatric surgery patients in pre and postoperative at Assiut University Hospital.

Null hypothesis (H0):

There is no relation between the physical activity among bariatric surgery patients in pre and postoperative at Assiut University Hospital.

\section{Aim of the Study:}

Evaluate the effectiveness of physical activity program for bariatric surgery patients through:

1. Assessing the bariatric surgery patient's needs.

2. Planning and implementing the educational program according to the bariatric surgery patient's needs.

3. Evaluating their improvement after implementing the program.

\section{Subjects and Methods}

Research design: Quasi-experimental research design (one-group pretest-posttest design) has been used in this study.

Setting: This study was carried out in an outpatient surgery clinic in the main Assuit University Hospital.

Sample: A convenient sample was used in this study which involved 70 preoperative bariatric surgery patients from 5/2019 until 10/2020. Individuals with a BMI $\geq$ of $40 \mathrm{~kg} / \mathrm{m} 2$ or between 35 and $40 \mathrm{~kg} / \mathrm{m} 2$ with comorbidities that could be improved by weight loss and aged (18-65) from both sexes were included.

Tools of study

Tool (I) Interview Structured Questionnaire which included two parts:

Part one: Personal characteristics such as; name, age, sex, marital status, residence, height, weight, and Body Mass Index (BMI).

Part Two: It included past and present medical history, duration of obesity, history of body weight loss, and chronic diseases.

Tool (II): International physical activity questionnaire (Arabic version) (Fogelholm et al., 2006) which used as a self-administered format and divided into five subscales:

Part 1: Job-related physical activity included patients' work as paid jobs, farming, volunteer work, course work, and any other unpaid work that they did outside the home. It did not include unpaid work, which might do around the home.

Part 2: Transportation physical activity: it involved how the patients traveled from place to place, including places like work, stores, movies, and so on.

Part 3: Housework, house maintenance, and caring for the family: This partition included the physical activities, which have been done in the last 7 days in and around the home, like housework, gardening, yard work, general maintenance work, and caring for the family.

Part 4: Recreation, sport, and leisure-time physical activity: This segment was about all the physical activities that they did in the last 7 days solely for recreation, sport, exercise, or leisure.

Part 5: Time spent sitting: The last questions were about the time they spend sitting while at work, at home, while doing coursework, and during leisure time. This may include time spent sitting at a desk, visiting friends, reading, or sitting or lying down to watch television.

Scoring the International Physical Activity Questionnaire (IPAQ)

Three levels of physical activity are proposed as low, middle, and high physical activity or as a continuous variable (MET minutes a week). MET minutes represent the amount of energy expended carrying out physical activity.

A MET is a multiple of the estimated resting energy expenditure. One MET is what the patients expended when they were at rest. Therefore, 2 METS was twice what they expended at rest. Walking was considered to be 3.3 METS, moderate physical activity to be 4 METS, and vigorous physical activity to be 8 METS

Methods of data collection

Pilot study: The pilot study was performed before starting data collection on ten patients; who were included in the study; to investigate the clearness of the questions and to assess the required time to answer the questionnaire.

Educational program:

Health education aimed to design, implement and evaluate the effectiveness of the physical activity program among bariatric surgery patients and maintain weight stability.

Preparation phase: An official consent letter was obtained from the Dean of the Faculty of Nursing, Assiut University to the director of the main Assiut University Hospital. The researcher designed the educational program after a literature review about morbid obesity and physical activity then the final form of the proposed program was checked by a panel of experts of medical surgical nursing staff, community nursing staff, and patients to assess the program outline, objectives, strategy, and evaluation plans. Their considerations preplanning and rewriting of the content were carried out according to the views set by the experts. 
The program's specific objectives were:

1. Educate patients on how to keep their weight control to the average normal range.

2. Motivate patients toward modification of their lifestyle towered physical exercise and its role in maintaining a healthy weight to promote stability of weight loss.

3. Explore the importance and different types of PA. The health education program was including the normal range of weight, dangers of overweight and obesity, the importance of physical exercise, duration of physical exercise per day, and types of physical exercise.

Planning phase: The arrangement of conducting the program was done during this stage; the sessions and time of the education program were decided according to the patient presented in the outpatient clinic. It may include 1-2 patients in each session according to patients who prepared for bariatric surgery.

Teaching Time: the time of teaching during the weighting time in the outpatient clinic and the coordination between the researcher and participants.

Teaching place: The program was conducted at an outpatient surgery clinic. Other facilities were checked and arranged during this phase as the teaching place, audiovisual aids, handout.......etc.

\section{Ethical consideration:}

Research proposal approved by the ethical committee in the faculty of Nursing, Assiut University. There was no risk for the study subject during the application of the research. The study followed common ethical principles in clinical research. Oral consent was obtained from patients that are willing to participate in the study, after explaining the nature and purpose of the study. Confidentiality and anonymity were assured.

Implementation phase: The researcher started to collect data in May 2019; data stopped from October 2020 because the work stopped in the outpatient surgery clinic from $1 / 2020$ to $5 / 2020$ as a consequence of Covid 19. The researcher met the patients in the surgical clinic for one day per week. It was done in 3 sessions each, followed by arranging for the education program schedule based on the contents of the program, the number of patients prepared for surgery, time availability.

The first session: Before beginning the first session, an orientation of the program and its purpose were done and patients were informed about the time and place of the session taken. Pretest was used before the implementing educational program during this stage the researcher was prepared a handout given to every study participant. It includes a summarized all content of the program mention before.
The researcher introduced herself to the patient. The form was filled in by the researcher herself with every interviewed patient. Each interview took about (2530) minutes every week. Pretest (preoperative) was done which included detailed medical history anthropometric measurement and evaluate the patient's physical activity.

In the second session: the researcher explained to bariatric patients how to increase their daily physical activity, housework, house maintenance, care for family, recreation, and time spent.

Each session started with a summary of what was given during the previous session and the objectives of the new topics. The post-test for patients' was implemented by repeating the same format of the pretest to determine the effect of the implementation of the program and finally, a follow-up test was done immediately and late follow up after 3 months from the program.

Third session: in the evaluation phase, the effect of the educational program was evaluated by doing a follow-up posttest after 3 months by using the same questionnaire which used in the pretest.

Statistical analysis: The data obtained were reviewed, prepared for computer entry, coded, analyzed, and tabulated. Descriptive statistics (i.e., frequencies, percentage and mean, standard deviation, etc.) was done using the computer program SPSS version 22. Chi-square and exact fissure tests were used to compare differences in the distribution of frequencies among different groups. It is considered * significant when P-values were less than 0.05. Oneway analysis of variance (ANOVA), post hoc t-test, and Mann-Whitney U-test were used to test betweengroup differences. Paired samples t-test was done to compare quantitative data between pre-test and posttest while in case of non-parametric data, MannWhitney test was used to compare quantitative variables between two groups and Kruskal Wallis test for more than two groups. P-value considered statistics statistically significant when $\mathrm{P}<0.05$.

\section{Reliability:}

The internal consistency of the responses for each scale and the total tool calculated by using Cronbach $\alpha$ coefficient for the physical activity was $(0.767)$. 


\section{Results}

Table (1): Personal data of bariatric patients at outpatient's surgery clinic - Assuit University Hospital

\begin{tabular}{|c|c|c|}
\hline Socio-demographic data & No. (70) & $\%$ \\
\hline \multicolumn{3}{|l|}{ Age: (years) } \\
\hline$<30$ & 30 & 42.9 \\
\hline $30-40$ & 17 & 24.3 \\
\hline$>40$ & 23 & 32.9 \\
\hline Mean \pm SD (Range) & \multicolumn{2}{|c|}{$34.50 \pm 12.52(16.0-65.0)$} \\
\hline \multicolumn{3}{|l|}{ Sex: } \\
\hline Male & 21 & 30.0 \\
\hline Female & 49 & 70.0 \\
\hline \multicolumn{3}{|l|}{ Educational level: } \\
\hline Illiterate & 8 & 11.4 \\
\hline Read \& write & 1 & 1.4 \\
\hline Preparatory & 11 & 15.7 \\
\hline Secondary & 21 & 30.0 \\
\hline Intermediate institutes & 9 & 12.9 \\
\hline University graduate & 15 & 21.4 \\
\hline Postgraduate degree & 5 & 7.1 \\
\hline \multicolumn{3}{|l|}{ Occupation: } \\
\hline Nonworking/housewife & 39 & 55.7 \\
\hline Unskilled /Skilled manual worker & 5 & 7.1 \\
\hline Trades/business & 5 & 7.1 \\
\hline Semiprofessional & 18 & 25.7 \\
\hline Professional & 3 & 4.3 \\
\hline \multicolumn{3}{|l|}{ Residence: } \\
\hline Rural & 19 & 27.1 \\
\hline Urban & 51 & 72.9 \\
\hline
\end{tabular}

Table (2): Medical history of bariatric patients at outpatient's surgery clinic - Assuit University Hospital

\begin{tabular}{|l|c|c|}
\hline & No. (70) & \% \\
\hline Medical history & & 50.0 \\
\hline Diabetes & 35 & 74.3 \\
\hline Hypertension & 52 & 17.1 \\
\hline Infertility & 12 & 27.1 \\
\hline Cardiovascular disease & 19 & 2.9 \\
\hline Depression & 2 & 8.6 \\
\hline Sleep apnea & 6 & 74.3 \\
\hline Duration of obesity & & 25.7 \\
\hline Since childhood & 52 & 44.3 \\
\hline Recently & 18 & \\
\hline History of weight loss & 31 & \\
\hline
\end{tabular}

Table (3): Mean score of weight, height, and body mass index among the bariatric patients at outpatient's surgery clinic - Assuit University Hospital

\begin{tabular}{|l|c|}
\hline \multicolumn{1}{|c|}{ Items } & Mean \pm SD \\
\hline Height & $165.24 \pm 7.59$ \\
\hline Weight & $124.89 \pm 17.80$ \\
\hline BMI (pretest) & $45.79 \pm 6.13$ \\
\hline BMI (posttest) & $36.91 \pm 5.47$ \\
\hline P-value & $0.000^{*}$ \\
\hline
\end{tabular}


Table (4): Mean statistical differences of physical activity (pre \& post-test) among the bariatric patients at outpatient's clinic surgery - Assiut University Hospital

\begin{tabular}{|c|c|c|c|}
\hline \multirow{2}{*}{ Physical activity } & Pretest $(n=70)$ & $\operatorname{Post}-\operatorname{test}(n=70)$ & \multirow{2}{*}{ P-value } \\
\hline & No. $(\%)$ & No. $(\%)$ & \\
\hline \multicolumn{4}{|l|}{ Work: } \\
\hline Low & $48(68.6)$ & $18(25.7)$ & \\
\hline Moderate & $8(11.4)$ & $18(25.7)$ & $0.000^{*}$ \\
\hline High & $14(20.0)$ & $34(48.6)$ & \\
\hline \multicolumn{4}{|l|}{ Transportation: } \\
\hline Low & $65(92.9)$ & $10(14.3)$ & \\
\hline Moderate & $5(7.1)$ & $46(65.7)$ & $0.000^{*}$ \\
\hline High & $0(0.0)$ & $14(20.0)$ & \\
\hline \multicolumn{4}{|l|}{ Domestic: } \\
\hline Low & $54(77.1)$ & $27(38.6)$ & \\
\hline Moderate & $14(20.0)$ & $26(37.1)$ & $0.000 *$ \\
\hline High & $2(2.9)$ & $17(24.3)$ & \\
\hline \multicolumn{4}{|l|}{ Leisure time: } \\
\hline Low & $69(98.6)$ & $18(25.7)$ & \\
\hline Moderate & $1(1.4)$ & $37(52.9)$ & $0.000 *$ \\
\hline High & $0(0.0)$ & $15(21.4)$ & \\
\hline \multicolumn{4}{|l|}{ Total physical activity: } \\
\hline Low & $57(81.4)$ & $5(7.1)$ & \\
\hline Moderate & $12(17.1)$ & $40(57.1)$ & $0.000 *$ \\
\hline High & $1(1.4)$ & $25(35.7)$ & \\
\hline
\end{tabular}

* Significant difference at $p$. value $<0.05$

Table (5): Relation between personal data and physical activity mean score (pre and post-test) among bariatric patients at outpatient's surgery clinic - Assuit University Hospital

\begin{tabular}{|c|c|c|}
\hline \multirow{3}{*}{ Personal data } & \multicolumn{2}{|c|}{ Physical activity score } \\
\hline & Pre-test & Post-test \\
\hline & Median (IQR) & Median (IQR) \\
\hline \multicolumn{3}{|r|}{ 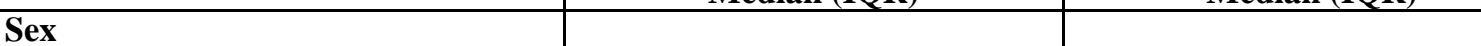 } \\
\hline Male & $91.9(56.3-630.0)$ & $1561.5(974.6-2188.9)$ \\
\hline Female & $195.0(92.3-453.8)$ & $1148.3(972.4-1576.5)$ \\
\hline P-value & 0.251 & 0.211 \\
\hline \multicolumn{3}{|l|}{ Age (years) } \\
\hline$<30$ & $269.6(91.9-541.9)$ & $1568.6(1009.8-1986.8)$ \\
\hline $30-40$ & $93.8(61.9-195.0)$ & $1003.5(732.8-1177.5)$ \\
\hline$>40$ & $151.9(63.8-476.6)$ & $1267.5(974.6-1860.4)$ \\
\hline P-value & 0.182 & $0.023^{*}$ \\
\hline \multicolumn{3}{|l|}{ Educational level } \\
\hline$<$ Secondary & $131.4(60.4-827.5)$ & $1107.8(973.5-2327.6)$ \\
\hline Secondary & $170.3(63.8-453.8)$ & $1212.0(778.5-1498.9)$ \\
\hline$>$ Secondary & $189.0(76.9-424.9)$ & $1333.9(974.6-1748.3)$ \\
\hline P-value & 0.988 & 0.699 \\
\hline \multicolumn{3}{|l|}{ Residence } \\
\hline Rural & $453.8(115.5-1129.5)$ & $1498.9(1003.5-2611.5)$ \\
\hline Urban & $275.1(126.6-721.9)$ & $2421.8(1753.1-3421.6)$ \\
\hline P-value & $0.012 *$ & 0.249 \\
\hline \multicolumn{3}{|l|}{ Occupation } \\
\hline Not working & $180.0(91.9-445.5)$ & $1177.5(972.4-1943.4)$ \\
\hline Working & $151.9(61.9-519.5)$ & $1333.9(871.5-1860.4)$ \\
\hline P-value & 0.745 & 0.827 \\
\hline
\end{tabular}

* Significant difference at $p$. value $<0.05$ 
Table (1): Showed that the largest number of bariatric patients were female (70\%), $42.9 \%$ of them aged $<30$ also, $55.7 \%$ of them were nonworking/housewives. according to their educational level, $11 \%$ of the studied sample were illiterate while $30.0 \%$ of them were secondary educated.

Table (2): Showed the distribution of bariatric surgery patients according to their past and present medical history at outpatient's clinic surgery in Assuit University Hospital, the largest number of patients (74.3\%) complained from hypertension, $(50.0 \%)$ half of them were diabetic, $17.1 \%$ patients suffered from a history of infertility and $27.1 \%$ had cardiovascular disease. According to the history of obesity, $74.3 \%$ suffered since childhood, $25.7 \%$ of them were recently had obesity.

Table (3): According to weight, height, and body mass index among the studied bariatric surgery patients, table (2) illustrated that the mean height and weight of them were $(165 \pm 7.59), \&(124.89 \pm 17.80)$ respectively also Body mass index was (45.79 \pm 6.13).

Table (4): According to bariatric surgery patients (pre \& post-test) related to physical activity score, this table illustrated that the mean pre-test physical activity score was a statistically significant difference with a mean score of post-test (P-value $=0.000)$. Also, it showed that $1.4 \%$ of bariatric surgery had high physical activity in pretest while in posttest was increased $35.7 \%$ had high physical activity.

Table (5): Demonstrated that there was a statistically significant $(\mathrm{P}-\mathrm{value}=0.012)$ relation between residences and the mean score of physical activity of bariatric patients in pretest and posttest there was a significant relationship between age and the mean score of physical activity $(\mathrm{P}$-value $=0.023)$.

\section{Discussion}

Bariatric surgery is now considered an effective treatment option for severe and complex obesity and is recommended by national bodies such as the National Institute for Health and Care Excellence (Nuijten et al., 2021). Healthy behaviors include a regular physical activity which plays an important role in preventing excess weight gain (Hall \& Guo, 2017).

Design, implement and evaluate the physical activity program among bariatric surgery patients. The findings of the present study showed that the range of bariatric patient's ages was (18-65) years and the mean age was $34.50 \pm 12.52$. Also, it showed that the prevalence of obesity was significantly higher in females than males. Moreover, it showed that more than one-tenth of them had an illiterate level of education while more than one-fifth had university graduates. According to patients' residences, less than three quarters were from urban areas while more than one-quarter lived in rural areas.

This study agreed with Omar et al., 2020 who stated that females represent the majority of the participants who complained of obesity. Moreover, this finding agreed with Alebshehy et al., 2016 who mentioned that in Egypt, there is a remarkable increase in obesity with more than one-third of the whole population being obese. A particular issue in Egypt is that prevalence of obesity is more than double among females as compared to males. Also, Ahmed et al., 2016 reported that the prevalence of obesity was higher in female patients but male patients are onefifth.

Women are more affected than men because of their anatomy, physiology, and metabolism which predispose them to obesity, in addition to the fact that in Africa, they often have a sedentary lifestyle of central obesity than males based on BMI and number of the sample (two-third to one third). Moreover, it has been reported that the prevalence of obesity in adults is very high in Egypt, particularly among women (Mehanna et al., 2020).

In contrast to our result, Chung et al., 2018 who conducted the study in South Korea, and Reilly et al., 2018, found significantly elevated levels of obesity in men compared with women. In my opinion, the contrast between our study and those studies came from the differences in sample size. In addition, there were different socioeconomic circumstances in the countries. Moreover, the researchers in those studies used other tools to detect the prevalence in the two sexes.

According to bariatric patients' residence, the results of the present study agreed with Tabrizi et al., 2018 who conducted the study in Iran, and Mawaw et al., 2017 who mentioned that overweight and obesity were prevalent in the urban area and urbanization has been significantly associated with obesity. According to the review of literature, it cleared that Increasing in obesity prevalence is related to the significant differences in lifestyle in particular dietary habits and limited physical activity in urban-rural regions

In the pretest, the body mass index was $45.79 \pm 6.13$ while, after three months from bariatric surgery, BMI was $36.91 \pm 5.47$. Those results agreed with Mohamed et al., 2018 who found that BMI was $37.98 \pm 1.24$ among the studied sample. Moreover Ali et al. $2019 \&$ Yang et al. 2017 mentioned that the diagnosis of these obese subjects was achieved based on the calculation of body mass index (BMI) beyond $30 \mathrm{~kg} / \mathrm{m} 2$. Also, the results agreed with Olsén et al., 2021 who conducted a study under the title " Longterm effects of physical activity prescription after bariatric surgery: A randomized controlled trial" and 
found that BMI in preoperative was 43.5 (4.4) while after two months from operation, it became 36.6 (3.6).

Those studies followed the World Health Organization classification which includes that grade I obesity BMI $=30-34.9 \mathrm{~kg} / \mathrm{m} 2$, grade II obesity BMI $=35-39.9 \mathrm{~kg} / \mathrm{m}$ 2, and morbid obesity BMI $\geq 40 \mathrm{~kg} / \mathrm{m}$ 2.

The present study showed that there were slightly less than three-quarters of patients who complained of hypertension, half of them were diabetic, less than one-fifth suffered from a history of infertility and more than one quarter had cardiovascular disease.

These findings were similar to the study conducted by Ajlouni et al., 2021 who mentioned that obesity was significantly associated with increased odds of diabetes mellitus, hypertension, elevated triglycerides, and low high-density lipoprotein cholesterol after adjusting for age. Also, the results agreed with Olsén et al., 2021 who found that blood pressure was higher in a preoperative while after two months from operation, it became within normal range.

Obese patients are a major risk factor for many chronic diseases including heart disease, cancer, kidney failure, pulmonary disease, and diabetes. Being overweight can impede the management of chronic conditions and is the second-highest contributor to the burden of disease.

According to the physical activity score (pre \& posttest) for bariatric surgery patients, the mean pre-test physical activity score was a statistically significant difference with a mean score of post-test (Pvalue $=0.000$ ). Also, it showed that more than one percent of them had high physical activity in pretest while in posttest more than one third had high physical activity.

The results of the present study agreed with Olsén et al., 2021 who found that the intervention group increased its physical activity 6-months postoperatively. Also, Lawson et al., 2020 who conducted a study under the title" Physical activity and psychosocial correlates following bariatric surgery among patients with loss-of-control eating" and stated that more than ten percent reported engaging in no self-reported physical activity, less than one fifth reported engaging in only mild activity (no moderate or strenuous bouts), more than one third reported engaging in at least one moderate bout (but no strenuous bouts), and less than two-fifths reported at least one bout of strenuous activity.

Furthermore, Baillot et al. 2018 who conducted a study under the title "Effects of a pre-surgery supervised exercise training 1 year after bariatric surgery: a randomized controlled study" and mentioned that the physical activity of the studied sample increased from light and moderate, also found an improvement in walking cardiac response and functional strength. In another study published by King \& Bond, 2013 stated that before surgery the majority of bariatric surgery patients are highly sedentary and inactive. While in postoperative many patients reported an increase in their PA.

Additionally, Tettero et al, 2018 showed significant increases in leisure and sport activity at 24 months postoperative compared to baseline $(\mathrm{P}<0.001)$. But a small significant decrease was seen in the work component at 24 months compared to baseline ( $\mathrm{P}<$ $0.001)$

Increasing PA pre- to postoperatively and higher postoperative PA level are associated with greater weight loss, improved body composition, and improved fitness following surgery (King ; Bond 2013 \& Tettero et al, 2018). A Cochrane review that evaluated 41 randomized controlled trials with a total of 3476 overweight or obese participants has concluded that PA alone induced significant weight loss (Al-Hazzaa, 2016).

Evidence-based practice suggested that physical activity might provide important health benefits after bariatric surgery which included improve physical fitness and metabolic health.

The current study demonstrated that there was a significant relation between residences and the mean score of physical activity in the pretest $(\mathrm{P}$-value $=$ 0.012). While in the posttest there was a significant relationship between age and the mean score of physical activity $(\mathrm{P}$-value $=0.023)$.

This result agreed with Herman et al., 2014 who mentioned that age, sex, smoking status, pre-surgery body mass index, time-since-surgery, and percent excess weight loss were significantly associated with PA and/or sitting outcomes. Also, it agreed with Sultana et al., 2021 who mentioned that physical activity was significant with the level of education Pvalue $(0.000 *)$ and residence $\mathrm{P}$-value $(0.004 *)$.

\section{Conclusion}

In the light of the present study results, it can be concluded that physical exercise instructions in the postoperative management of patients appear to increase PA and maintain weight loss after bariatric surgery.

\section{Recommendation}

1. Educational programs about physical activity at all levels should be implemented and especially for obese persons.

2. Other tools for measuring physical activity are necessary to optimize the validity of the exercise data for bariatric patients. 
3. Further studies are needed to confirm these hypotheses with a larger sample size.

Acknowledgments:

The researchers would like to thank all participated patients and all departments of surgery employees.

\section{References:}

- Ahmad A, Carleton JD, Ahmad ZF, Agarwala A. (2016): Laparoscopic versus robotic-assisted Rouxen-Y gastric bypass: a retrospective, single-center study of early perioperative outcomes at a community hospital. Surg Endosc. 2016 Sep;30(9):3792-6. DOI: 10.1007/s00464-015-4675y. Epub 2015 Dec 10. PMID: 26659234.

- Ajlouni, K., Khader, Y., Batieha, A., Jaddou, H., \& El-Khateeb, M. (2021): An alarmingly high and increasing prevalence of obesity in Jordan. Epidemiology and Health, 42, 1-7. https://doi.org/10.4178/epih.e2020040

- Alebshehy, R., Shuaib, N. M., Mbako, J. D., Barffo, D., \& Nuotol, R. K. (2016): Determinant Analysis of Obesity among Adult Females in Egypt. The Egyptian Journal of Hospital Medicine, 65(1), 662-669. https://doi.org/10.12816/0033779

- Al-Hazzaa HM. (2016): Physical activity prescription before bariatric surgery: Feasibility, health impacts, and practical implications. Saudi J Obesity 2016;4:3-12

- Ansari, W. El, \& Elhag, W. (2021): Weight Regain and Insufficient Weight Loss After Bariatric Surgery: Definitions, Prevalence, Mechanisms, Predictors, Prevention and Management Strategies, and Knowledge Gaps - a Scoping Review. Obesity Surgery $2021 \quad 31: 4, \quad 31(4), \quad$ 1755-1766. https://doi.org/10.1007/S11695-020-05160-5

- Baillot A, Vallée CA, Mampuya WM, Dionne IJ, Comeau E, Méziat-Burdin A, \& Langlois MF. (2018): Effects of a Pre-surgery Supervised Exercise Training 1 Year After Bariatric Surgery: a Randomized Controlled Study. Obes Surg. 2018 Apr;28(4):955-962. DOI: 10.1007/s11695-0172943-8. PMID: 28963710.

- Bellicha, A., van Baak, M., Battista, F., Beaulieu, K., Blundell, J., Busetto, L., Carraça, E., Dicker, D., Encantado, J., Ermolao, A., FarpourLambert, N., Pramono, A., Woodward, E., \& Oppert, J. (2021): Effect of exercise training before and after bariatric surgery: A systematic review and meta-analysis. Obesity Reviews: An Official Journal of the International Association for the Study of Obesity. https://doi.org/10.1111/OBR.13296

- Chung W, Kim J, Lim Sj, \& Lee S (2018): Sexspecific role of education on the associations of socioeconomic status indicators with obesity risk: A population-based study in South Korea. PLOS ONE
13(1):

e0190499. https://doi.org/10.1371/journal.pone.019 0499

- Fogelholm, M., Malmberg, J., suni, J., Santtila, M., Kyröläinen, H., Mäntysaari, M., \& Oja, P. (2006): International Physical Activity Questionnaire. Medicine \& Science in Sports \& Exercise, 38(4), 753-760. https://doi.org/10.1249/01.mss.0000194075.16960.2 0

- Hall, K., \& Guo, J. (2017): Obesity Energetics: Body Weight Regulation and the Effects of Diet Composition. Gastroenterology, 152(7), 17181727.e3. https://doi.org/10.1053/J.GASTRO.2017.01.052

- Herman KM, Carver TE, Christou NV, \& Andersen RE. (2014): Physical activity and sitting time in bariatric surgery patients $1-16$ years postsurgery. Clin Obes. 2014 Oct;4(5):267-76. DOI: 10.1111/cob.12069. Epub 2014 Aug 7. PMID: 25825859.

- Kawafha, M. (2013): The Role of Community Health Nurse in Obesity Policy Development. Australian Journal of Basic and Applied Sciences, 7(8), 237-246.

- King, W., \& Bond, D. (2013): The importance of preoperative and postoperative physical activity counseling in bariatric surgery. Exercise and sport sciences reviews, 41(1), 26-35. https://doi.org/10.1097/JES.0b013e31826444e0

- Köhler, H., Dorozhkina, R., Gruner-Labitzke, K., \& De Zwaan, M. (2020): Specific Health Knowledge and Health Literacy of Patients before and after Bariatric Surgery: A Cross-Sectional Study. Obesity Facts, 13(2), 166-178. https://doi.org/10.1159/000505837

- Lawson, J., Kerrigan, S., Meagan M. Carr, Ashley A. Wiedemann, Valentina Ivezaj, \& Carlos M. Grilo (2020): Physical activity and psychosocial correlates following bariatric surgery among patients with loss-of-control eating, Mental Health, and Physical Activity, Volume 19, 100343

- Mawaw, P., Yav, T., Mukuku, O., Lukanka, O., Kazadi, P., Tambwe, D., Omba, J., Kakoma, J. B., Bangs, M., \& Luboya, O. (2017): Prevalence of obesity, diabetes mellitus, hypertension and associated risk factors in a mining workforce, Democratic Republic of Congo. The Pan African medical journal, 28, 282. https://doi.org/10.11604/pamj.2017.28.282.14361

- Mehanna, A., Ali, M., Dabbous, N., \& Tayel, K. (2020): Knowledge of Female University Students about Obesity and its Adverse Effects on Reproductive Health. Journal of High Institute of Public Health, 2020; 50(1): 18-24. DOI: 10.21608/jhiph.2020.81234 
- Mohamed RA, Yousef AM \& Ata HK(2018): Effect of electro-acupuncture versus low-level laser therapy on lipid profile in obesity. Phys Ther Rehabil. 2018; 5:9. http://dx.doi.org/10.7243/20552386-5-9

- Nuijten, M., Tettero, O., Wolf, R., Bakker, E., Eijsvogels, T., Monpellier, V., Hazebroek, E., Janssen, I., \& Hopman, M. (2021): Changes in Physical Activity in Relation to Body Composition, Fitness and Quality of Life after Primary Bariatric Surgery: a Two-Year Follow-Up Study. Obesity Surgery, 31(3), 1120-1128. https://doi.org/10.1007/s11695-020-05009-x

- Olsén, M., Wiklund, M., Sandberg, E., Lundqvist, S., \& Dean, E. (2021): Long-term effects of physical activity prescription after bariatric surgery: A randomized controlled trial. Physiotherapy Theory and Practice, 00(00), 1-11. https://doi.org/10.1080/09593985.2021.1885087

- Omar, S., Taha, Z., Hassan, A., Al-Wutayd, O., \& Adam, I. (2020): Prevalence and factors associated with overweight and central obesity among adults in Eastern Sudan. PloS One, 15(4). https://doi.org/10.1371/JOURNAL.PONE.0232624

- Pearce, C., Rychetnik, L., Wutzke, S., \& Wilson, A. (2019): Obesity prevention and the role of hospital and community-based health services: a scoping review. BMC Health Services Research $201919: 1, \quad 19(1), \quad 1-16$. https://doi.org/10.1186/S12913-019-4262-3

- Pouwels, S., Sanches, E., Cagiltay, E., Severin, R., \& Philips, S. (2020): Perioperative Exercise Therapy in Bariatric Surgery: Improving Patient Outcomes. Diabetes, metabolic syndrome, and obesity: targets and therapy, 13, 1813-1823. https://doi.org/10.2147/DMSO.S215157

- Reilly JJ, El-Hamdouchi A, Diouf A, Monyeki A, \& Somda SA. (2018): Determining the worldwide prevalence of obesity. Lancet. 2018 May 5;391(10132):1773-1774. DOI: 10.1016/S01406736(18)30794-3. PMID: 29739565.

- Sabera Sultana, Md Mizanur Rahman, Byron Sigel, \& Masahiro Hashizume, (2021): Associations of lifestyle risk factors with overweight or obesity among adolescents: a multicountry analysis, The American Journal of Clinical Nutrition, Volume 113, Issue 3, March 2021, Pages 742-750, https://doi.org/10.1093/ajcn/nqaa337

- Tabrizi JS, Sadeghi-Bazargani H, Farahbakhsh M, Nikniaz L, \& Nikniaz Z. (2018): Prevalence and Associated Factors of Overweight or Obesity and Abdominal Obesity in Iranian Population: A Population-based Study of Northwestern Iran. Iran J
Public Health. 2018 Oct;47(10):1583-1592. PMID: 30524990 ; PMCID: PMC6277719.

- Tettero OM, Aronson T, Wolf RJ, Nuijten MAH, Hopman MTE, \& Janssen IMC. (2018): Increase in Physical Activity After Bariatric Surgery Demonstrates Improvement in Weight Loss and Cardiorespiratory Fitness. Obes Surg. 2018 Dec;28(12):3950-3957. DOI: 10.1007/s11695-0183439-x. PMID: 30105664; PMCID: PMC6223746.

- Upton, J. (2017): Obesity and the nurse's role: reducing health inequalities through health promotion. Links to Health and Social Care, 2(2), 39-51. http://openjournals.ljmu.ac.uk/lhsc

- Vuori, I. (2018): World Health Organization and Physical Activity. Progress in Preventive Medicine, 3(1), e0012. https://doi.org/10.1097/PP9.0000000000000012

- WHO. (2021): Obesity and overweight. https://www.who.int/news-room/factsheets/detail/obesity-and-overweight

- Yang Q, Xiao T, Guo J, \& Su Z. (2017): Complex Relationship between Obesity and the Fat Mass and Obesity Locus. Int J Biol Sci. 2017 May 15;13(5):615-629. DOI: 10.7150/ijbs.17051. PMID: 28539834; PMCID: PMC5441178. 